\title{
Problemáticas y estrategias para la intervención y gestión en centros históricos de Italia, España y América Latina
}

Alejandra González Biffis

Arquitecta. Doctoranda, becaria de investigación CONICET con sede en el Centro de Investigaciones Urbanas y Territoriales y docente de la cátedra Teorías y Planificación Territorial López-Rocca-Etulain (LRE) Nivel I, de la Facultad de Arquitectura y Urbanismo, Universidad Nacional de La Plata.

gonzalezbiffisale@yahoo.com.ar.

\section{Juan Carlos Etulain}

Arquitecto. Doctor en Urbanismo, Universidad de Buenos Aires, investigador adjunto CONICET con sede en el Centro de Investigaciones Urbanas y Territoriales. Director del doctorado y profesor adjunto Taller Vertical de Arquitectura FPE, cátedra Teorías y Planificación Territorial LRE, de la Facultad de Arquitectura y Urbanismo, Universidad Nacional de La Plata. jcetulain@hotmail.com.

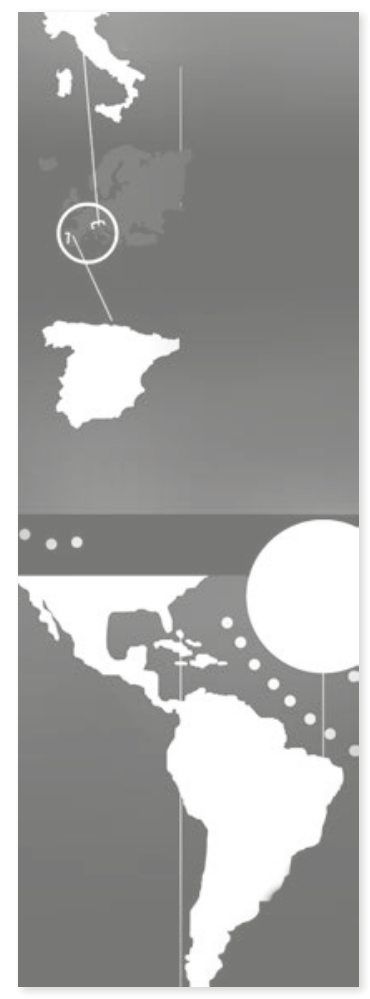




\begin{abstract}
Resumen
El tema abordado surge de la línea de investigación vinculada con las intervenciones destinadas a la recuperación de Centros Históricos, que desde la década del 70 a la actualidad cobraron un papel relevante y pasaron a tener un rol destacado, dado que su reactivación plantea nuevos desafios, perspectivas y formas de actuar en ellos. En este sentido, el artículo presenta las estrategias de intervención y gestión desarrolladas a partir de la implementación de proyectos urbanos en estas áreas históricas de ciudades grandes e intermedias de Italia, España y América Latina, en el período de estudio mencionado. Se analizan las problemáticas que las impulsaron, las similitudes y diferencias de sus Centros Históricos, y se destacan las estrategias e instrumentos de intervención y gestión implementados; se identifican las experiencias integrales y los vínculos e influencias entre ellos. La metodología empleada es de alcance descriptivo y clasificatorio, basada en la identificación de casos.
\end{abstract}

\title{
Palabras clave
}

Centros históricos; urbanismo sostenible; problemáticas; estrategias de intervención y gestión; experiencias integrales.

\begin{abstract}
Issues and Strategies Used for Projects and their Management in Historic Centers of Italy, Spain and Latin Amertica.

The subject of this paper emerges from a research project related to development actions aimed at the recovery of Historical Town Centers. From the 1970's to the present these activities cquired significant relevance, and their reactivation means new challenges, perspectives and operational means of action. In this sense, this paper proposes to review the operation and management strategies developed through the Projects that have been implemented in these historic areas of large and intermediate cities of Italy, Spain and Latin America, during the study period mentioned. The analytical emphasis is on the Historic Centers' problems that have driven these Projects, the similarities and differences of these Centers, and the strategies and operational tools of action and management used. The overall experiences, and the links and influences between them are highlighted. The methodology used is descriptive and classificatory, based on the identification of cases.
\end{abstract}

\section{Keywords}

Historical centers; Sustainable Urbanism; Problems; Intervention and management strategies; Integral Experiences. 


\section{Introducción}

El abandono o degradación de los Centros Históricos (en adelante, $\mathrm{CH}$ ) por motivos bélicos, políticos o por el mismo crecimiento de las ciudades que ha conllevado la aparición de nuevas centralidades constituye la condición previa para el inicio de procesos de intervención en estas áreas centrales. Estos procesos se llevaron a cabo mediante diversas estrategias de conservación y transformación, procurando mejorar el funcionamiento de estos sectores urbanos transmisores de significados, memoria e identidad.

En Europa, el interés por la recuperación de los $\mathrm{CH}$ comienza en el siglo XX a finales de la década del 60, pero con motivo de la crisis del sector de la construcción y la crisis urbana del 70, es recién a partir de los años 80 cuando comienzan a ponerse en práctica muchas intervenciones, aunque algunos planes ya habían sido elaborados en la década del 70 . Entre las décadas de los 80 y 90, comienza a intervenirse también en América Latina (en adelante $\mathrm{AL}$ ), y desde ese momento a la actualidad, es posible verificar cómo los cambios que atravesaron las sociedades influyeron en la forma de ver y actuar sobre la ciudad, hechos que incidieron en los modos de planificar y gestionar estos sectores urbanos.

El artículo plantea inicialmente, en forma sintética, el marco teórico-conceptual que influyó en el desarrollo de las estrategias de intervención y gestión en el contexto europeo (Italia y España), y en AL en el período comprendido desde la década del 70 hasta la actualidad. Se presentan las experiencias seleccionadas y la metodología de análisis. Posteriormente, se desarrolla una mirada global de los casos, destacando problemáticas recurrentes en los $\mathrm{CH}$ y los nuevos enfoques en los modos de intervenir y gestionar estas áreas históricas. Finalmente, se elaboran consideraciones haciendo hincapié en la relación entre problemáticas, intervenciones y estrategias, los vínculos, influencias y relaciones identificadas entre los casos, así como el reconocimiento de experiencias integrales y de cuestiones y aspectos aún pendientes de resolver. 
1. Gustavo Giovannoni, arquitecto, urbanista e ingeniero italiano, uno de los importantes teóricos de la restauración.

2. Carta Italiana del Restauro, Roma, 1931, una de las siete cartas de

restauro que establecen recomendaciones para las intervenciones. Desarrolla el problema del repristino o copia sin elementos básicos que lo amparen, así como la copia como base de la restauración.

3. Carta de Gubbio, 1960.

Orienta actuaciones para

el conjunto de la ciudad histórica, dejando atrás la

idea del edificio aislado.

4. Carta de Venecia,1964. Plantea una síntesis del problema urbano y patrimonial defendiendo la autenticidad sobre "falsos históricos", y la valoración del monumento y su entorno.

5. Carta Europea del Patrimonio Arquitectónico,1975.

Dedica atención especial

al valor cultural, socialy económico del patrimonio cultural.

6. PRGC: Piano Regolatore Generale Comunale. Instrumento de planificación que regula la actividad edifica-

toria a escala municipal.

7. ICOMOS: Consejo Internacional de Monumentos y Sitios.

\section{Enfoques para la intervención, marcos legales} e influencias entre Europa y América Latina

Son numerosas las teorías de conservación y restauro que se han desarrollado a lo largo del tiempo y que tuvieron un gran aporte con la Escuela Italiana de Restauro del siglo XIX, cuna de intelectuales como Camillo Boito, Luca Beltrami, Cesare Brandi, Gustavo Giovannoni ${ }^{1}$ (S. XX). Este último realizó un gran aporte a la comprensión del patrimonio urbano, interpretando que la ciudad, los barrios y otros sectores urbanos deben conservarse, entendiéndolos como "monumentos vivos", considerando a la ciudad como contenedora de vida y defendiendo un equilibrio entre aquello que conservar y renovar, manteniendo el carácter social de la población. Las ideas de Giovannoni, incluidas en la Carta Italiana del Restauro de $1931^{2}$, anticipan las políticas aplicadas en Europa desde la década de 1960. Las cartas publicadas en el siglo XX (Carta de Gubbio, 19603; Carta de Venecia ${ }^{4}$, 1964; Carta Europea del Patrimonio Arquitectónico ${ }^{5}$, 1975) y las convenciones internacionales sobre patrimonio arquitectónico y urbano juegan un rol significativo en la intervención del patrimonio, y generan interesantes debates sobre los modos de ver e intervenir la ciudad.

La Carta de Gubbio (1960) afirma la importancia de que las intervenciones sean parte de la planificación urbanística, mediante Planos Reguladores Generales Municipales (PRGC ${ }^{6}$ ). Propone también la creación de Planes de Restauración Conservadora (Risanamento Conservativo) como planes detallados de iniciativa municipal (Piano Particolareggiato), con el fin de fijar la modalidad de intervención sobre el conjunto, y sostiene que dentro de estos planes debe brindarse una atención especial a la identificación de la estructura social que caracteriza a los barrios, protegiendo la vivienda y las actividades comerciales existentes. En este marco, surgen los primeros planes italianos en CH como Padova (1953), Siena (1954), Assisi (1956), Urbino (1958), Nápoles (1961), Roma (1962), Bolonia (1969), Venecia (1979). Entre ellos, se destaca el Plan de Bolonia, Piano di edilizia Economica e Popolare (1973), que conceptualizó términos como "Monumento", "Entorno Monumental" o "CH", a favor de la idea global de "Ciudad” (Cervellatti-Sacannavini, 1973).

A su vez, la creación de ICOMOS ${ }^{7}$ y la aparición de asociaciones como "Italia Nostra" y ANCSA han contribuido a la interpretación y valorización de este contexto. En la actualidad, se 


\section{Problemáticas y estrategias para la intervención y gestión en centros históricos de Italia, España y América Latina}

habla de "conservación" o "rehabilitación integral del CH", con la idea de CARLO CESARI (1993) de que proteger el pasado no significa cristalizar o museificar, sino garantizar el crecimiento progresivo de la cultura actual, a través del conocimiento y el disfrute de los testimonios que produjo esta civilización.

El requerimiento de la UNESCO de Planes de Gestión a los CH Patrimonio de la Humanidad incentivó en Italia el establecimiento por ley en el año 2006 de dichos planes, que se desarrollan en concordancia con el PRGC del sistema jurídico italiano, que cada ciudad italiana debe cumplir desde el año 1942, acorde con la ley.

Por su parte, en España, a finales de los años 70 con los primeros ayuntamientos democráti$\cos$, los $\mathrm{CH}$ se suman a los movimientos de recuperación de las áreas históricas que estaban surgiendo en Europa, y se desarrollan, según expresa SANTAMARíA ComALLONGA (2013), políticas de renovación y rehabilitación para la revitalización de los CH. Las primeras proponían la adaptación del $\mathrm{CH}$ a nuevas funciones y actividades, que producirían una transformación completa del entorno urbano, con cambios morfológicos, funcionales, estructurales y sociales de las zonas afectadas, cuyos impactos dieron lugar a mediados de los 70 a la aparición de políticas de rehabilitación urbana, que han puesto énfasis en la conservación del entorno urbano con una mirada más social, intentando frenar el despoblamiento y la segregación residencial.

Estos cambios en las estrategias de intervención fueron acompañados por transformaciones en los instrumentos para intervenir. Como explica Valenzuela Rubio (2000), para ello se crearon instrumentos operacionales (PERI o PEPRI ${ }^{8}$ ) en los que la planificación física era protagonista, pero se había superado el período de conservacionismo extremo para entender al CH en su totalidad (con población y actividades incluidas).

Gaja Díaz (2001) y Pol Méndez (1993) sostienen que las políticas planteadas y experimentadas en Italia fueron "Referencias" para las propuestas en España, que tomaron indicaciones de Bolonia para muchos $\mathrm{CH}$. Sin embargo, la especificidad de las ciudades españolas hizo que no fuera aplicable el "modelo italiano" de conservación morfológica y recuperación tipológica. Desde hace décadas han empezado a generarse posturas opuestas a la conservacionista, a favor de intervenciones de transformación, con interés por la forma urbana, el desarrollo de proyectos a escalas intermedias, la construcción
8. PERI: Plan Especial de Reforma Interior. PEPRI: Plan Especial de Protección $y$ Reforma Interior. 
9. URBAN: Programas destinados a desarrollos innovadores para la regeneración de áreas mediante proyectos de habitabilidad, espacio público, transporte e integración social. del plan a partir de proyectos urbanos, el debate sobre la cualidad de las arquitecturas y el reconocimiento del papel estructurante del espacio público.

En cuanto a las políticas urbanas y territoriales, durante los años 90 se implementaron numerosos programas precursores de los programas URBAN 9 . Han involucrado numerosas actuaciones en Italia y España, que según TroITIÑo VINUESA (2003), en relación con los primeros estudios del período democrático, mostraron importantes mejoras en la valoración de la dimensión histórico-cultural de la ciudad, en los métodos de análisis de la realidad urbana y también en las técnicas y modelos de intervención urbanística.

En el contexto latinoamericano, el abandono y degradación de los $\mathrm{CH}$ impulsados por el crecimiento de las ciudades y por políticas públicas orientadas en la periferia fueron disparadores de diversas actuaciones en CH. Rodríguez Alomá (2013) reconoce que en AL se elaboró una serie de documentos que contribuyeron en la mirada y las formas de intervenir en los CH: Coloquio de Quito y Carta de Machu Picchu, 1977; Declaratoria de Bogotá, 1978; Declaración de México, 1985; Carta de Petrópolis, 1987 - fuera de AL, Carta de Washington del mismo año-y Carta de Veracruz, 1992. Incorporaron cambios conceptuales en la forma de actuar con temas como las políticas de conservación integral, la pertenencia de los habitantes a los centros, la planificación urbana y la participación ciudadana, la vivienda social, la cultura y la identidad, las industrias culturales y las políticas de gestión (Rodríguez Alomá, 2008).

Pero recién en los 90 se observa un cambio en la intervención de los $\mathrm{CH}$. Su reconocimiento como lugar patrimonial valioso, con una localización privilegiada, generó un paulatino retorno del interés hacia el centro incorporando nuevos actores. El binomio crisis-oportunidad encontró en el patrimonio material e inmaterial un activo económico fundamental con miras a la sostenibilidad socioeconómica.

A diferencia del contexto europeo, donde no necesariamente las actuaciones son desencadenantes de nombramientos de Patrimonio de la Humanidad por la UNESCO, en el ámbito de AL la mayoría de las intervenciones y de los planes maestros surgieron como respuesta a esa nominación. No obstante, las últimas propuestas para la elaboración de planes de Sector han sido de ciudades sin nombramiento, lo que significa un avance en la interpretación de la ciudad. 


\section{Experiencias de intervención y gestión}

La mirada a los $\mathrm{CH}$ de ciudades grandes e intermedias de AL, España e Italia permite la identificación de numerosas intervenciones, que enmarcadas dentro de un plan han intentado recuperar áreas que por mucho tiempo permanecieron en estado de abandono y degradación. El recorte de los casos a ciudades de Italia, España y AL se fundamenta en la gran cercanía que los países latinoamericanos han mantenido históricamente con estos países europeos. Los lazos con España comenzaron con el descubrimiento de América, y se potenciaron a lo largo del tiempo con las colonizaciones, y siglos más tarde, con las importantes oleadas migratorias que los países latinoamericanos recibieron de este país, así como sucedió también con los inmigrantes italianos debido a las guerras mundiales. Estos territorios comparten muchos aspectos y elementos culturales (lengua, religión, costumbres y tradiciones), que indudablemente se ven reflejados en el desarrollo de las ciudades, donde pueden reconocerse características y problemáticas comunes.

Al mismo tiempo, Italia ha sido uno de los países con mayor trayectoria en cuanto a la intervención del patrimonio, un referente indiscutido en la temática. Los vínculos mencionados previamente son la causa por la que varias fuentes de financiamiento para el desarrollo de intervenciones urbanas en AL provienen de instituciones públicas europeas.

En las páginas siguientes se presenta el análisis elaborado a partir de cuarenta casos seleccionados, en el período de estudio (ver cuadros 1a y 1b). Metodológicamente, el criterio de selección utilizado se guió por los siguientes aspectos:

- Que las intervenciones desarrolladas y propuestas para sus $\mathrm{CH}$ se encontraron enmarcadas en un instrumento de planificación.

- Que los casos sean representativos de las diversas etapas del urbanismo por las que se atravesó tanto en el contexto europeo (Italia y España) como en el latinoamericano.

- Que se encuentren distribuidos en forma equitativa en la extensión del país o región.

- Que la ciudad registre relevancia política, económica, cultural o histórica a nivel local o internacional.

- Que la escala de ciudad y su cantidad de habitantes sean representativas.

- Que la actuación haya tenido un alto impacto, positivo o negativo, a escala local o internacional.

- Que el nivel de información sea suficiente para la realización del análisis. 


\begin{tabular}{|c|c|c|c|c|c|c|c|}
\hline \multicolumn{3}{|l|}{ Tabla 1} & \multicolumn{3}{|c|}{ CONTEXTO EUROPEO: CASOS ITALIANOS SELECCIONADOS } & \multicolumn{2}{|c|}{ ente: elaboración propia, 2017} \\
\hline REGIÓN & $\mathrm{N}^{0}$ & CIUDAD & INTERVENCIÓN & $\begin{array}{l}\text { INSTRUMENTO DE } \\
\text { PLANIFICACIÓN }\end{array}$ & $\begin{array}{l}\text { DECLARACIÓN } \\
\text { UNESCO }\end{array}$ & POBLACIÓN & $\begin{array}{l}\text { NIVEL } \\
\text { INFO }\end{array}$ \\
\hline & & & & \multicolumn{4}{|c|}{ Patrim. Human. } \\
\hline CAMPANIA & 1 & NÁPOLES & REVITALIZACIÓN & $\begin{array}{l}\text { 2011, PLAN DE GESTIÓN DEL } \\
\text { CH PLAN DE ACCIÓN } \\
\text { LOCAL (URBAN) }\end{array}$ & AÑo 1995 & 971.849 hab. & MUY BUENO \\
\hline EMILIA ROMAGNA & 2 & BOLOGNA & REHABILITACIÓN & $\begin{array}{l}\text { 1973, PIANO DI EDILIZIA } \\
\text { ECONOMICA POPOLARE } \\
\text { (Cervellati - Sacannavini) }\end{array}$ & $\begin{array}{l}\text { 1996, Ciudad } \\
\text { Creativa }\end{array}$ & 371.217 hab. & MUY BUENO \\
\hline LAZIO & 3 & ROMA & RECUALIFICACIÓN & $\begin{array}{c}\text { 2003, NUOVO PIANO } \\
\text { REGOLATORE GENERALE }\end{array}$ & AÑO 1980 & 2.872.082 hab. & BUENO \\
\hline LIGURIA & 4 & GÉNOVA & $\begin{array}{l}\text { REHABILITACIÓN / } \\
\text { REGENERACIÓN } \\
\end{array}$ & $\begin{array}{c}\text { 2001, PIANO OPERATIVO } \\
\text { DEL CH } \\
\end{array}$ & NO POSEE & 594.904 hab. & MUY BUENO \\
\hline LOMBARDÍA & 5 & MILÁN & $\begin{array}{l}\text { RECUALIFICACIÓN / } \\
\text { REGENERACIÓN }\end{array}$ & $\begin{array}{c}\text { 2012, PIANO URBANISTICO } \\
\text { DI MILANO }\end{array}$ & NO POSEE & 1.345 .890 hab. & BUENO \\
\hline PIEMONTE & 6 & TORINO & REGENERACIÓN & $\begin{array}{l}\text { 2011, URBAN BARRIERA DI } \\
\text { MILANO - PROGRAMA INTEGRADO } \\
\text { DE DESARROLLO LOCAL }\end{array}$ & NO POSEE & 911.823 hab. & MUY BUENO \\
\hline SICILIA & 7 & PALERMO & $\begin{array}{l}\text { RECUPERACIÓN / } \\
\text { CONSERVACIÓN }\end{array}$ & $\begin{array}{l}\text { 1993, PIANO PARTICOLARE- } \\
\text { GGIATO ESECUTIVO DEL CH } \\
\text { (Cervellati - Benevolo) }\end{array}$ & 2015 (sector) & 860.000 hab. & MUY BUENO \\
\hline \multirow{2}{*}{ TOSCANA } & 8 & FIRENZE & PRESERVACIÓN & $\begin{array}{l}\text { 2016, PIANO DI GESTIONE } \\
\text { DEL CH }\end{array}$ & AÑo 1982 & 378.236 hab. & MUY BUENO \\
\hline & 9 & SIENA & $\begin{array}{c}\text { TUTELA / CONSERVACIÓN } \\
\text { I VALORIZACIÓN }\end{array}$ & $\begin{array}{l}\text { 2015, PIANO DI GESTIONE } \\
\text { DEL SITO UNESCO CH }\end{array}$ & AÑo 1995 & 52.774 hab. & MUY BUENO \\
\hline VENETO & 10 & VENEZIA & $\begin{array}{l}\text { PROTECCIÓN I } \\
\text { REHABILITACIÓN }\end{array}$ & $\begin{array}{l}\text { 2012, PIANO DI GESTIONE DI } \\
\text { VENEZIA E LA SUA LAGUNA } \\
\text { (PIANO REGOLATORE GENERALE 1999) }\end{array}$ & AÑO 1987 & 270.884 hab. & MUY BUENO \\
\hline
\end{tabular}

Por otra parte, el análisis reconoce las intervenciones o proyectos urbanos según pertenezcan a distintas generaciones o familias relacionadas con los paradigmas que guiaron al urbanismo en las últimas décadas. En los 80, en el marco del Urbanismo Morfologista, Fragmentario y Operacional; en los 90, dentro del Urbanismo Empresarial, Productivista y Especulativo; y a comienzos del siglo XXI, en el marco de un paradigma embrionario caracterizado como Urbanismo Sostenible, que incorpora junto a la revalorización de la lógica social (enfoque del Derecho a la Ciudad) la razón ecológica, donde el Proyecto Urbano entiende la intervención en la ciudad a partir de la "necesidad" (EtUlain-GonzÁLEZ BIFFIS, 2014). 


\section{Problemáticas y estrategias para la intervención y gestión en centros históricos de Italia, España y América Latina}

\begin{tabular}{|c|c|c|c|c|c|c|c|}
\hline \multicolumn{3}{|l|}{ Tabla 1} & \multicolumn{3}{|c|}{ CONTEXTO EUROPEO: CASOS ESPAÑOLES SELECCIONADOS } & \multicolumn{2}{|c|}{ dente: elaboración propia, 2017} \\
\hline REGIÓN & $\mathbf{N}^{0}$ & CIUDAD & INTERVENCIÓN & $\begin{array}{l}\text { INSTRUMENTO DE } \\
\text { PLANIFICACIÓN }\end{array}$ & $\begin{array}{l}\text { DECLARACIÓN } \\
\text { UNESCO }\end{array}$ & POBLACIÓN & $\begin{array}{l}\text { NIVEL } \\
\text { INFO }\end{array}$ \\
\hline \multicolumn{8}{|c|}{ Patrim. Human. } \\
\hline \multirow{2}{*}{ ANDALUCÍA } & 11 & MÁLAGA & REHABILITACIÓN / REVITALIZACIÓN & $\begin{array}{l}\text { 1990, PLAN ESPECIAL DE } \\
\text { PROTECCIÓN Y REFORMA } \\
\text { INTERIOR (PEPRI) }\end{array}$ & NO POSEE & 575.322 hab. & MUY BUENO \\
\hline & 12 & SEVILLA & REHABILITACIÓN & $\begin{array}{l}\text { 1994, PLAN ESPECIAL DE } \\
\text { PROTECCIÓN DEL CENTRO } \\
\text { HISTORICO (PEPCH) }\end{array}$ & NO POSEE & 693.878 hab. & BUENO \\
\hline ARAGÓN & 13 & ZARAGOZA & REVITALIZACIÓN & $\begin{array}{l}\text { 1997, PLAN INTEGRAL DEL } \\
\text { CASCO HISTÓRICO (PICH) }\end{array}$ & NO POSEE & 664.953 hab. & BUENO \\
\hline ASTURIAS & 14 & GIJÓN & RECUPERACIÓN & $\begin{array}{l}\text { 1985, PLAN ESPECIAL DEL } \\
\text { CASCO HISTÓRICO (PECH) }\end{array}$ & NO POSEE & 273.422 hab. & ESCASO \\
\hline CASTILLA Y LEÓN & 15 & VALLADOLID & RECUALIFICACIÓN / REGENERACIÓN & $\begin{array}{l}\text { 1997, PLAN ESPECIAL DEL } \\
\text { CENTRO HISTÓRICO (PECH) }\end{array}$ & NO POSEE & 301.876 hab. & BUENO \\
\hline CATALUNIA & 16 & BARCELONA & REHABILITACIÓN & $\begin{array}{c}\text { 1987, PLAN DE } \\
\text { REHABILITACIÓN INTEGRAL }\end{array}$ & NO POSEE & 1.608.746 hab. & BUENO \\
\hline GALICIA & 17 & LA CORUÑA & PROTECCIÓN / REF. INT. / REHAB. & $\begin{array}{l}\text { 2012, REVISIÓN PLAN ESPECIAL } \\
\text { PROTECCIÓN Y REFORMA } \\
\text { INTERIOR DE LA CIUDAD VIEJA }\end{array}$ & NO POSEE & 215.227 hab. & BUENO \\
\hline MADRID & 18 & MADRID & REHABILITACIÓN & $\begin{array}{c}\text { 2004, PLAN DE ACCIÓN PARA } \\
\text { LA REVITALIZACIÓN DEL } \\
\text { CENTRO URBANO }\end{array}$ & NO POSEE & 3.165.541 hab. & MUY BUENO \\
\hline PAÍS VASCO & 19 & $\begin{array}{l}\text { VITORIA } \\
\text { GASTEIZ }\end{array}$ & REHABILITACIÓN & $\begin{array}{l}\text { 1983, PERI / 2009, PLAN DE } \\
\text { REACTIVACIÓN INTEGRAL DEL } \\
\text { CENTRO HISTÓRICO (URBAN) }\end{array}$ & NO POSEE & 242.223 hab. & MUY BUENO \\
\hline VALENCIANA & 20 & ALCOY & REHABILITACIÓN & $\begin{array}{l}\text { 1989, PLAN GRAL. DE ORDE- } \\
\text { NACIÓN URBANA / PLAN ESPE- } \\
\text { CIAL PROTECCIÓN Y REF. INT. }\end{array}$ & NO POSEE & 61.542 hab. & BUENO \\
\hline
\end{tabular}

En este contexto, metodológicamente se analizaron las relaciones entre ellos identificando períodos del urbanismo en los que se enmarcan, y se tomaron referentes de intervenciones desarrolladas en el ámbito del Urbanismo Morfologista, por suyo aporte a la temática no podían obviarse, pero se hizo hincapié principalmente en aquellas intervenciones enmarcadas en la transición entre el Urbanismo Empresarial y el Urbanismo Sostenible, por las nuevas miradas que aportan a la planificación contemporánea, al formar parte de un sistema de planificación o una estrategia general de gestión de la ciudad. No obstante, en algunos ejemplos el aspecto temporal no necesariamente los sitúa dentro de un paradigma, sino que existen casos por cuya postura frente al $\mathrm{CH}$ mantuvieron siempre una visión más 


\begin{tabular}{|c|c|c|c|c|c|c|c|}
\hline \multicolumn{3}{|l|}{ Tabla 1} & \multicolumn{2}{|c|}{ CONTEXTO LATINOAMERICANO: CASOS SELECCIONADO } & \multicolumn{3}{|c|}{ Fuente: elaboración propia, 2017} \\
\hline REGIÓN & $\mathbf{N}^{\circ}$ & CIUDAD & INTERVENCIÓN & $\begin{array}{l}\text { INSTRUMENTO DE } \\
\text { PLANIFICACIÓN } \\
\end{array}$ & $\begin{array}{l}\text { DECLARACIÓN } \\
\text { UNESCO } \\
\end{array}$ & POBLACIÓN & $\begin{array}{l}\text { NVEL } \\
\text { INFO }\end{array}$ \\
\hline & & & & \multicolumn{4}{|c|}{ Patrim. Human. } \\
\hline ARGENTINA & 21 & $\begin{array}{l}\text { BUENOS } \\
\text { AIRES }\end{array}$ & REVITALIZACIÓN & $\begin{array}{l}\text { 2015, PLAN DE MANEJO DEL } \\
\text { CASCO HISTÓRICO }\end{array}$ & NO POSEE & 2.965.000 hab. & BUENO \\
\hline BOLIVIA & 22 & \begin{tabular}{|c|} 
SANTA CRUZ \\
DE LA SIERRA \\
\end{tabular} & REVITALIZACIÓN & \begin{tabular}{|l|} 
2008, PLAN DE REVITALIZACIÓN \\
INTEGRAL CENTRO HISTÓRICO \\
\end{tabular} & NO POSEE & 2.453.549 hab. & BUENO \\
\hline & 23 & RECIFE & REVITALIZACIÓN & \begin{tabular}{|c|} 
1980, PLANO DE \\
REVITALIZAÇAO DEL CENTRO
\end{tabular} & NO POSEE & 1.538.000 hab. & ESCASO \\
\hline BRASIL & 24 & $\begin{array}{l}\text { SALVADOR } \\
\text { DE BAHIA }\end{array}$ & REVITALIZACIÓN & $\begin{array}{c}\text { 1991, PROGRAMA DE } \\
\text { RECUPERAÇAO DEL CENTRO } \\
\text { HISTÓRICO DE SALVADOR, } \\
\text { PELOURINHO } \\
\end{array}$ & AÑO 1985 & 2.675.000 hab. & BUENO \\
\hline COLOMBIA & 25 & $\begin{array}{l}\text { CARTAGENA } \\
\text { DE INDIAS } \\
\end{array}$ & REVITALIZACIÓN & $\begin{array}{c}\text { 2008, PLAN DE REVITALIZACIÓN } \\
\text { DEL CENTRO HISTÓRICO }\end{array}$ & AÑO 1984 & 845.801 hab. & BUENO \\
\hline COSTA RICA & 26 & $\begin{array}{l}\text { SAN JOSÉ DE } \\
\text { COSTA RICA }\end{array}$ & REVITALIZACIÓN & $\begin{array}{c}\text { 2015, PLAN DE ACCIÓN } \\
\text { (DE REVITALIZACIÓN) } \\
\text { DEL CENTRO HISTÓRICO } \\
\end{array}$ & NO POSEE & 288.054 hab. & MUY ESCASO \\
\hline CUBA & 27 & LA HABANA & REVITALIZACIÓN & $\begin{array}{l}\text { 1994, PLAN MAESTRO / 2001, } \\
\text { PLAN ESPECIAL DE DESA- } \\
\text { RROLLO INTEGRAL DEL CH }\end{array}$ & AÑO 1982 & 2.105.000 hab. & MUY BUENO \\
\hline CHILE & 28 & SANTIAGO & RENOVACIÓN & $\begin{array}{c}\text { 1990, PROPUESTA DE } \\
\text { DESARROLLO PARA LA } \\
\text { RENOVACIÓN (PLAN DE } \\
\text { REPOBLAMIENTO) } \\
\end{array}$ & NO POSEE & 5.128.000 hab. & BUENO \\
\hline ECUADOR & 29 & QUITO & REHABILITACIÓN & $\begin{array}{c}\text { 1989, PLAN MAESTRO DE } \\
\text { REHABILITACIÓN INTEGRAL } \\
\text { DE LAS ÁREAS HISTÓRICAS }\end{array}$ & AÑO 1978 & 1.619 .000 hab. & MUY BUENO \\
\hline EL SALVADOR & 30 & $\begin{array}{c}\text { SAN } \\
\text { SALVADOR } \\
\end{array}$ & REVITALIZACIÓN & $\begin{array}{l}\text { 1998, PLAN DE RESCATE DEL } \\
\text { CENTRO HISTÓRICO (PRCSS) } \\
\end{array}$ & NO POSEE & 281.870 hab. & BUENO \\
\hline GUATEMALA & 31 & ANTIGUA & REHABILITACIÓN & \begin{tabular}{|} 
2012, PLAN MAESTRO DE LA \\
ANTIGUA GUATEMALA (PMAG) $/$ \\
PLAN DIRECTOR REHAB. CH
\end{tabular} & AÑO 1979 & 45.669 hab. & BUENO \\
\hline
\end{tabular}

enfocada en un Urbanismo Sostenible o los largos procesos de intervención fueron acompañando los distintos paradigmas (ver figura 1).

Este estudio permite identificar casos paradigmáticos, como Bolonia, Vitoria Gasteiz, Barcelona y Alcoy dentro del contexto europeo, y Salvador de Bahía, Quito y La Habana en AL, por ser representativos de los distintos períodos por los que atravesaron los $\mathrm{CH}$, por plantear nuevas miradas para afrontar la complejidad de los $\mathrm{CH}$ y constituir puntos de inflexión al configurar modelos o ejemplos que seguir, dentro de sus mismas regiones, así como en otros países. 
Problemáticas y estrategias para la intervención y gestión en centros históricos de Italia, España y América Latina

\begin{tabular}{|c|c|c|c|c|c|c|c|}
\hline \multicolumn{3}{|l|}{ Tabla 1} & \multicolumn{3}{|c|}{ CONTEXTO LATINOAMERICANO: CASOS SELECCIONADOS } & \multicolumn{2}{|c|}{ dente: elaboración propia, 2017} \\
\hline REGIÓN & $\mathbf{N}^{\circ}$ & CIUDAD & INTERVENCIÓN & $\begin{array}{l}\text { INSTRUMENTO DE } \\
\text { PLANIFICACIÓN } \\
\end{array}$ & $\begin{array}{c}\text { DECLARACIÓN } \\
\text { UNESCO }\end{array}$ & POBLACIÓN & $\begin{array}{l}\text { NIVEL } \\
\text { INFO } \\
\end{array}$ \\
\hline \multicolumn{8}{|c|}{ Patrim. Human. } \\
\hline HONDURAS & 32 & COMAYAGUA & REVITALIZACIÓN & \begin{tabular}{|c|} 
1995, PLAN MAESTRO \\
REVITALIZACIÓN CH / 1996, \\
PROG. COMAYAGUA COLONIAL
\end{tabular} & NO POSEE & 152.051 hab. & BUENO \\
\hline \multirow{2}{*}{ MÉXICO } & 33 & $\begin{array}{l}\text { CIUDAD } \\
\text { DE MÉXICO }\end{array}$ & REVITALIZACIÓN & $\begin{array}{l}\text { 2011, PLAN DE MANEJO } \\
\text { INTEGRAL DEL CENTRO } \\
\text { HISTÓRICO }\end{array}$ & AÑO 1987 & 8.851 .000 hab. & MUY BUENO \\
\hline & 34 & QUERÉTARO & PUESTA EN VALOR / CONSERVACIÓN & $\begin{array}{c}\text { 2008, PLAN DE MANEJO Y } \\
\text { CONSERVACIÓN DE LA ZONA } \\
\text { DE MONUMENTOS HISTÓRICOS }\end{array}$ & AÑO 1996 & 878.931 hab. & MUY BUENO \\
\hline PANAMÁ & 35 & PANAMÁ & REHABILITACIÓN / RESTAURACIÓN & $\begin{array}{l}\text { 2001, PLAN MAESTRO DE } \\
\text { REHABILITACION Y } \\
\text { RESTAURACION / 2004,PLAN } \\
\text { REVIVE EL CASCO } \\
\end{array}$ & AÑO 1997 & 880.691 hab. & BUENO \\
\hline PARAGUAY & 36 & ASUNCIÓN & REVITALIZACIÓN & $\begin{array}{l}\text { 2015, PLAN MAESTRO DE } \\
\text { REVITALIZACIÓN CENTRO }\end{array}$ & NO POSEE & 525.294 hab. & MUY BUENO \\
\hline PERÚ & 37 & LIMA & REHABILITACIÓN / RECUPERACIÓN & $\begin{array}{l}\text { 2014, PLAN MAESTRO DEL } \\
\text { CENTRO HISTÓRICO }\end{array}$ & AÑo 1991 & 8.473 .000 hab. & MUY BUENO \\
\hline $\begin{array}{l}\text { REPÚBLICA } \\
\text { DOMINICANA }\end{array}$ & 38 & $\begin{array}{l}\text { SANTO } \\
\text { DOMINGO }\end{array}$ & REVITALIZACIÓN & \begin{tabular}{|l|} 
2006, PLAN ESTRATÉGICO DE \\
REVITALIZACIÓN INTEGRAL DE \\
LA CIUDAD COLONIAL (PRICC) \\
\end{tabular} & AÑO 1990 & 965.040 hab. & BUENO \\
\hline URUGUAY & 39 & MONTEVIDEO & ORDENACIÓN / PROTECCIÓN / MEJORA & \begin{tabular}{|c|} 
2004, PLAN ESPECIAL DE \\
ORDENACIÓN, PROTECCIÓN Y \\
MEJORA DE LA CIUDAD VIEJA
\end{tabular} & NO POSEE & 1.305 .000 hab. & MUY BUENO \\
\hline VENEZUELA & 40 & MARACAIBO & RENOVACIÓN & $\begin{array}{l}\text { 1999, PLAN INTEGRAL DE } \\
\text { RENOVACIÓN URBANA DEL }\end{array}$ & NO POSEE & 1.339 .000 hab. & ESCASO \\
\hline
\end{tabular}

En la actual búsqueda de intervenciones que aspiren a un Urbanismo Sostenible, las estrategias e instrumentos de intervención y gestión se enfrentan con un gran reto, el "Desarrollo Sostenible”. Término empleado por primera vez en el año 1987 en el informe Brundtland ${ }^{10}$ elaborado para la ONU, y a partir del cual nace la confusión entre los términos "desarrollo sostenible" y "desarrollo sustentable". En este trabajo, adoptaremos el término "desarrollo sostenible" coincidiendo con WANDEMBERG Boschetti (2015), para quién el concepto implica un proceso en el tiempo y espacio y va de la mano de la eficiencia, lo cual le permite además ser eficaz, mientras que el "desarrollo sustentable" implica una finalidad (aquí/ahora) y va de la mano de la eficacia más no necesariamente de la eficiencia. Por tanto, un verdadero desarrollo sostenible implica por añadidura sustentabilidad, mas la sustentabilidad no im-

10. Informe resultado de la Comisión Mundial de Medio Ambiente y Desarrollo de Naciones Unidas, Asamblea de la ONU, 1983. plica necesariamente sostenibilidad. 


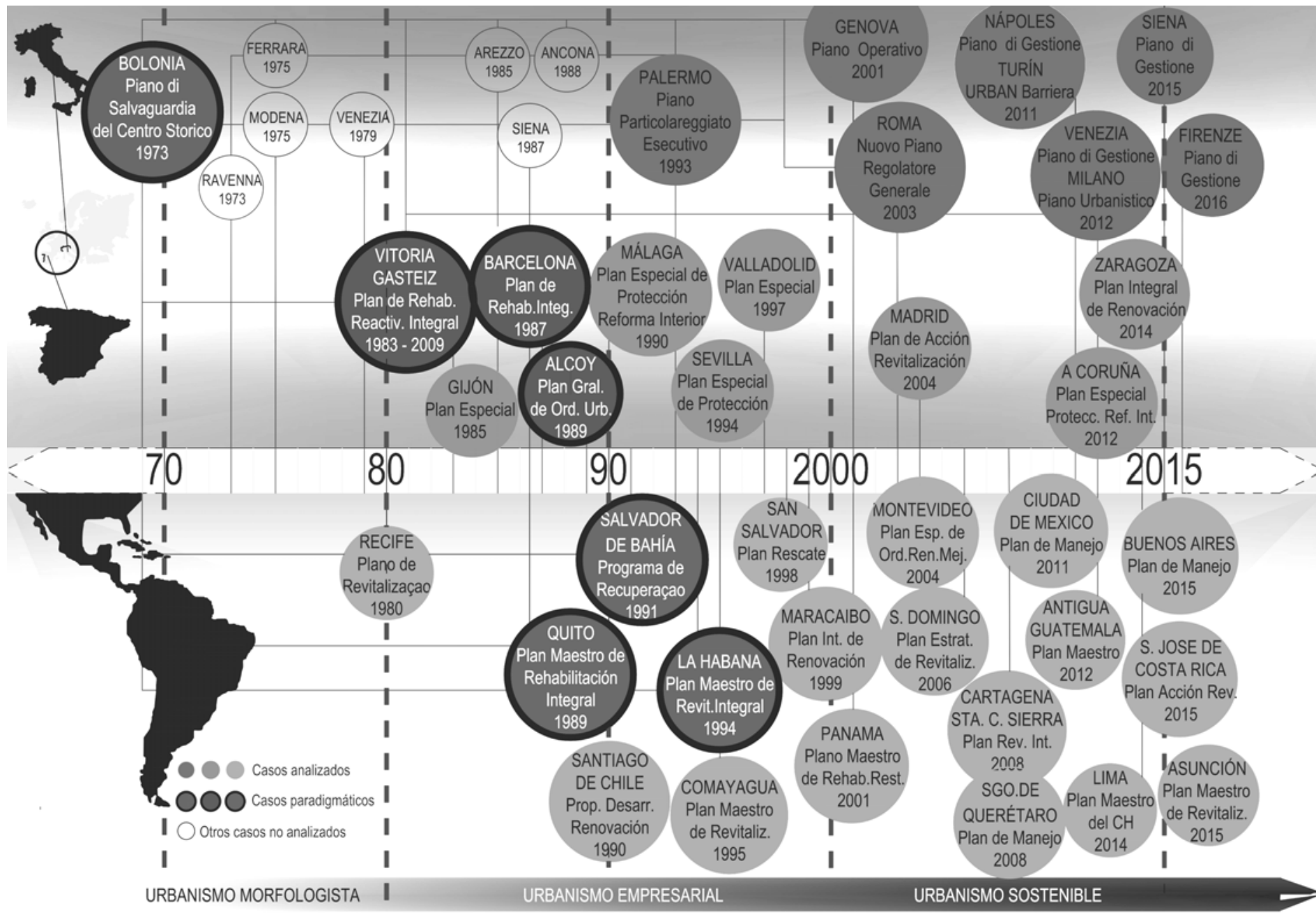

Figura 1. Casos seleccionados: encuadres, casos paradigmáticos e influencias. Fuente: elaboración propia, 2017 


\section{Problemáticas y estrategias para la intervención y gestión en centros históricos de Italia, España y América Latina}

Este concepto se basa en tres grandes pilares o dimensiones: ambiental, social y económica. Sin embargo, resulta difícil analizar el aspecto cultural como independiente del social. Sería más preciso hablar de una "dimensión socio-cultural", al mismo tiempo que se piensa a la "dimensión ambiental" como un conjunto de elementos físicos y naturales en continua interacción, considerándola por lo tanto como "dimensión físico-ambiental”. Finalmente, se tendrá en cuenta una cuarta dimensión que resulta clave, dado que engloba a las otras tres, y que posiciona a la gestión como medio para garantizar el funcionamiento y logro de los objetivos: la "dimensión institucional". En este marco, los casos seleccionados fueron analizados agrupándolos según problemáticas, intervenciones, estrategias e instrumentos teniendo en cuenta estas cuatro dimensiones: "físico-ambiental", "socio-cultural", "económica" e "institucional".

\section{Una mirada global de las experiencias}

\subsection{Problemáticas, intervenciones y estrategias}

Como verificamos en el estudio de los casos seleccionados, los $\mathrm{CH}$ de Italia, España y AL en general comparten las mismas problemáticas, pero difieren en la escala de estas, con mayor o menor gravedad acorde con la dimensión o la situación particular de algunas de las ciudades. Se realizó una selección de tipologías de problemas ${ }^{11}$, y se eligieron aquellos que se reiteran, siendo comunes a varios casos. Se podría afirmar que las problemáticas recurrentes son las siguientes:

\section{Dimensión físico-ambiental}

- Deterioro y pérdida del patrimonio construido (por ataques bélicos en Italia, por crecimiento de las ciudades en España y AL, por políticas de gobiernos dictatoriales y por las crisis de la década de 1980 con reconversiones productivas a nivel mundial).

- Carencia de viviendas sociales.

- Edificios abandonados (focos de concentración de problemas sociales).

- Falta de equipamientos y servicios.

- Pérdida de centralidad urbana.

- Pérdida de centralidad funcional (residencial, comercial y artesanal local).

- Sobre-utilización funcional.

- Elevada tugurización.

- Deficiencias en la movilidad y accesibilidad.

- Débil vinculación con el resto de la ciudad.
11. Que surgieron de la profundización, mediante planes y fuentes secundarias, en los conflictos que aquejaron a los $\mathrm{CH}$ de los casos de estudio. 
- Deterioro físico-ambiental por impacto del turismo.

- Desequilibrio funcional (diurno-nocturno o estacional).

- Alta exposición a desastres naturales.

Dimensión socio-cultural

- Gentrificación.

- Disminución de la población residente.

- Población envejecida (en CH de España e Italia).

- Escasa población.

- Desempleo.

- Marginalidad.

- Problemáticas sociales (drogadicción, prostitución, delincuencia, violencia).

- Pérdida de valores culturales.

- Exaltación o creación de atractivos culturales.

- Escasa valoración del espacio público.

- Ocupación / invasión del espacio público.

- Carencia de espacios verdes.

- Exaltación o creación de atractivos culturales.

Dimensión económica

- Disminución del comercio barrial y la artesanía local.

- Especulación inmobiliaria.

- Proliferación / incremento del comercio informal.

- Impactos negativos del turismo.

Dimensión institucional

- Falta de eficiencia institucional y de instrumentos de planificación y gestión.

- Deficiencias en los procesos de seguimiento y control.

- Falta de recursos para conservación y restauración.

Estas problemáticas han sido organizadas en las cuatro dimensiones, pero es preciso señalar la influencia y el impacto directo de unas sobre otras. Por ejemplo, los conflictos que se manifiestan en la dimensión físico-ambiental se reflejan en inconvenientes de la dimensión socio-cultural, que a su vez tienen origen en problemáticas económicas y, al mismo tiempo, toda esta serie de cuestiones encuentra correspondencia con deficiencias institucionales (ver figuras $2 \mathrm{a}$ y $2 \mathrm{~b}$ ). 


\section{Problemáticas y estrategias para la intervención y gestión en centros históricos de Italia, España y América Latina}

Se reconoce que las ciudades latinoamericanas presentan mayores dificultades en las cuatro dimensiones en relación con las ciudades de Italia y España. Especialmente en el aspecto socio-cultural, en el que existen problemas sociales muy marcados como exclusión social, delincuencia, violencia, drogadicción y prostitución, que si bien se reconocen en ciudades como Génova, Nápoles, Valladolid, resultan casos más puntuales. En el caso de Palermo en Italia, a la presencia de algunos de estos problemas se suma que ha estado dominada durante varios años por la mafia, que colaboró en generar abandono y destrucción de su $\mathrm{CH}$. En las ciudades de AL estas problemáticas sociales se encuentran más generalizadas y adquieren mayor gravedad, ya que llegan a serios problemas de criminalidad.

Por otra parte, el problema de la gentrificación afecta a ciudades de ambos contextos, está asociado principalmente al desarrollo del turismo y conlleva una museificación. Los casos más significativos en Europa son Venecia, Florencia, Barcelona; o Cartagena y Salvador de Bahía, en AL. En ciudades donde el turismo no representa la actividad central, la gentrificación se produce por recambio poblacional interno, producto de fluctuaciones en el mercado inmobiliario. A su vez, problemas sociales relacionados con la inmigración ilegal afectan tanto a Europa como a AL.

En las ciudades europeas la degradación física de los $\mathrm{CH}$ se ha encontrado más asociada con períodos dictatoriales, destrucciones bélicas, motivos criminales o reconversiones funcionales, como los casos del traslado del puerto en Gijón y Génova, que afectaron a los $\mathrm{CH}$ perdiendo centralidad, usos y presentando tejidos horadados por instalaciones portuarias abandonadas, que contribuyeron al abandono general. Por su parte en AL, el abandono ha estado más vinculado con constantes o repetidas crisis económicas, la falta de ingresos, que relacionada con la falta de desarrollo industrial, coloboró a que varios $\mathrm{CH}$ se conserven intactos. Aquellos $\mathrm{CH}$ más degradados tienen problemáticas de conservación del patrimonio. Otros con escasa tradición en la conservación del patrimonio afrontan el problema de la falta de valoración del $\mathrm{CH}$ por parte de la población residente y usuaria, así como el desinterés por su intervención, como en Comayagua, Santo Domingo, Maracaibo y Santa Cruz de la Sierra. Varios $\mathrm{CH}$ poseen una gran presencia de comercio informal, entre ellos Roma, Florencia, Venecia, Madrid, Barcelona, Cartagena, Quito, San Salvador, Comayagua, Ciudad de México, Lima y Maracaibo. 


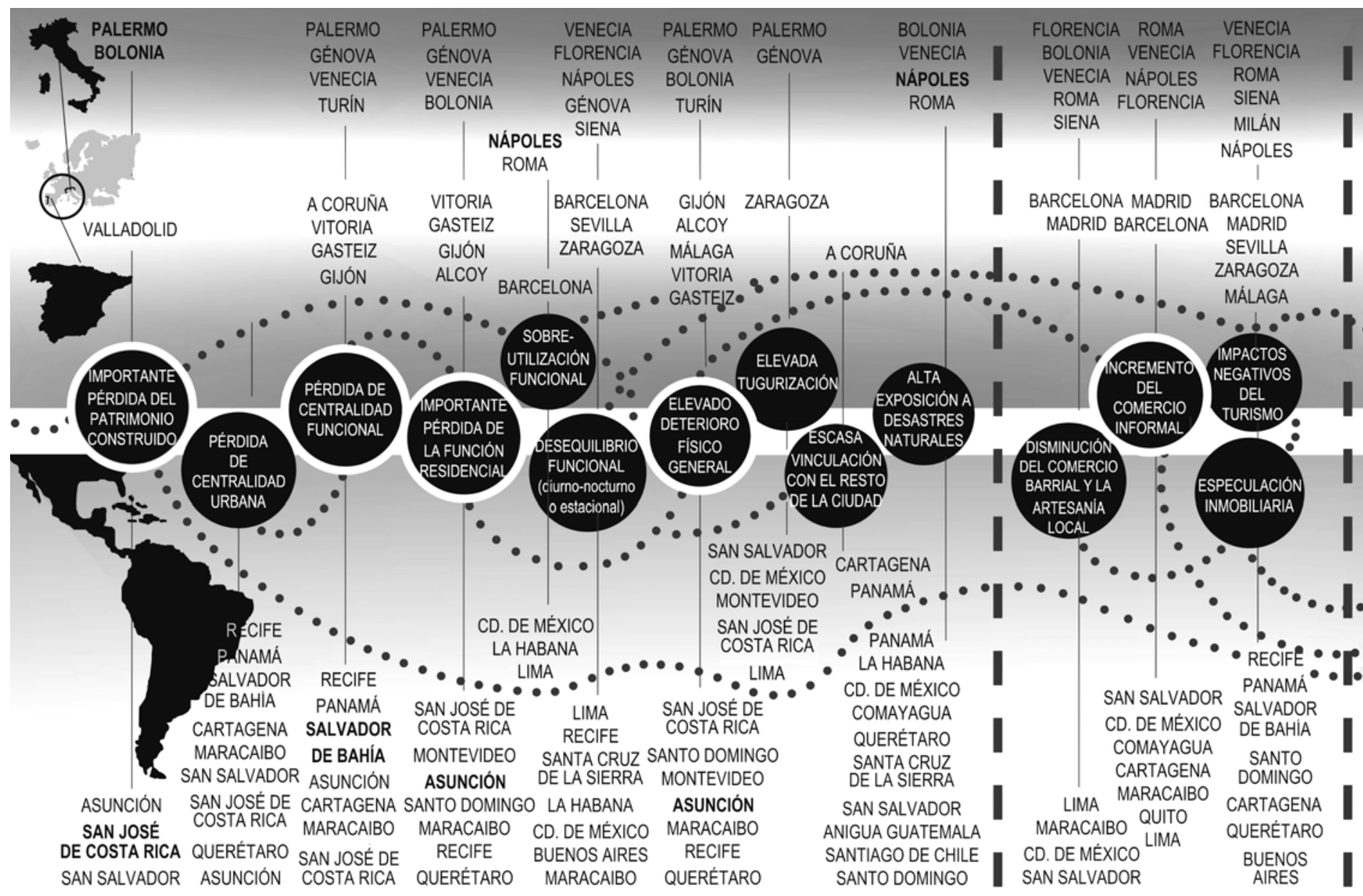

\section{DIMENSIÓN FISICO - AMBIENTAL}

Figuras 2.a. y 2.b. Problemáticas de los Centros Históricos (CH). Fuente: elaboración propia, 2017 
Problemáticas y estrategias para la intervención y gestión en centros históricos de Italia, España y América Latina

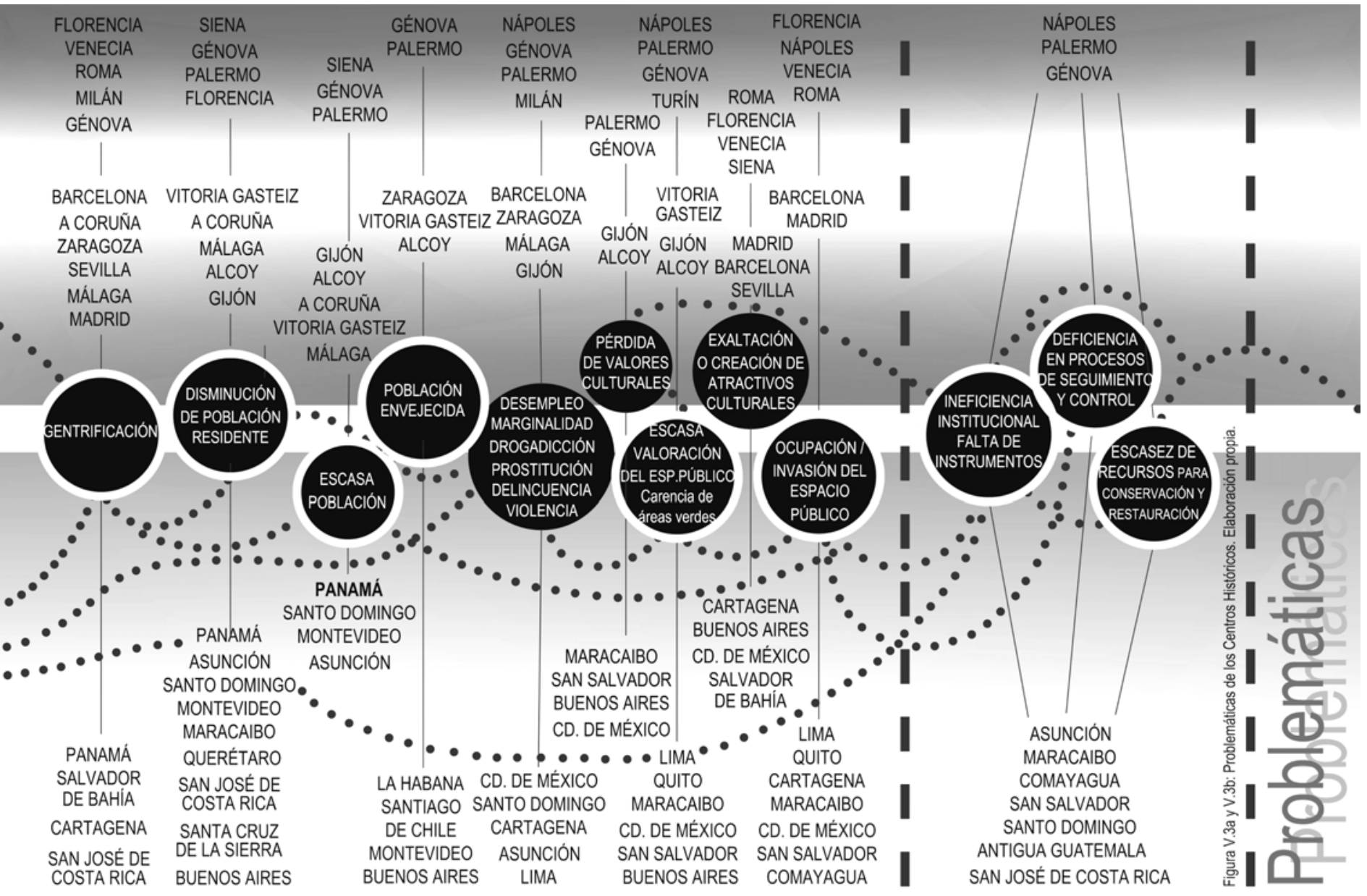

\section{DIMENSIÓN SOCIO - CULTURAL}

DIMENSIÓN INSTITUCIONAL 
12. Que han surgido del estudio de diversas fuentes de información para el análisis de las estrategias de los cuarenta casos.
También se verifica una doble situación, por un lado de despoblamiento en ciudades intermedias como Vitoria Gasteiz, Alcoy, Santo Domingo, San José de Costa Rica, o de superpoblamiento en ciudades centrales como Nápoles, Roma, La Habana, Ciudad de México o Lima, que presentan a su vez tugurización. Estas mismas ciudades registran también congestión vehicular y contaminación ambiental. En cuanto a la situación institucional, existen algunos casos en AL que presentan las condiciones más graves, aunque en general, salvo algunas excepciones, el panorama latinoamericano es débil en este aspecto.

Sin duda alguna, todo este conjunto de problemáticas ha contribuido al desarrollo de diversas intervenciones desde las administraciones públicas para su abordaje. Estas intervenciones se organizaron según tipologías o temáticas que las distintas ciudades abordaron en cada una de las dimensiones ${ }^{12}$, remarcando las influencias que cada una de ellas genera en distintos ámbitos y la relación que presentan con las problemáticas expuestas anteriormente.

Dentro de la dimensión físco-ambiental, se encontraron intervenciones que hacen hincapié en aspectos generales del patrimonio construido, y otras que dentro de él enfatizan en el espacio público, la vivienda, la movilidad y accesibilidad, la diversidad funcional, la recuperación de espacios vacantes e infraestructuras obsoletas, la mitigación de impactos de desastres naturales, la sosteniblidad medioambiental, la incorporación de nueva arquitectura, así como otras se enfocan en la conservación y la transformación.

En la dimensión económica, algunos casos se centraron en la sostenibilidad económica en general, y otros dirigen su mirada al turismo o al comercio informal. Con respecto a la dimensión socio-cultural, algunos casos implementaron intervenciones que abordan esta sostenibilidad desde distintos aspectos, y otros que han reforzado temas, como el repoblamiento, la apropiación del espacio público, la memoria y la identidad.

Por último, en la dimensión institucional se identificaron ejemplos que desarrollaron instrumentos tradicionales, otros que implementaron documentos requeridos por la UNESCO, algunos casos que aportaron instrumentos innovadores y finalmente ejemplos que recibieron financiamiento externo (ver figuras $3 a \mathrm{y} 3 \mathrm{~b}$ ). 
La constante búsqueda de soluciones a problemáticas reiteradas ofrece experiencias innovadoras que, más allá de enmarcarse para este análisis dentro de dimensiones particulares, repercuten en el entramado de temas que conjuga un CH. La implementación de estas intervenciones contribuye al desarrollo de diversas estrategias e instrumentos de intervención y gestión desde las administraciones públicas para su abordaje.

A continuación, se sintetizan como hallazgos identificados las estrategias empleadas, tomando como referencia la clasificación de intervenciones contemporáneas propuestas por Gaja Díaz (2001), quien sostiene que desde la década del 70 hasta la actualidad se han desarrollado estrategias conservacionistas (restauración, protección, rehabilitación, recuperación y esponjamiento) o transformadoras (reforma interior, renovación, reestructuración, recualificación y tercerización). A su vez, en los casos estudiados se reconocen otras estrategias más integrales (regeneración, revitalización y reconversión) con una elevada implementación en actuaciones recientes, que incorporan y combinan ambas estrategias.

\section{Estrategias conservacionistas}

- Conservación / preservación: Palermo 1993, Venecia 2012, Siena 2015, Florencia 2016.

- Protección, tutela, valorización: Siena 2015, A Coruña 2012, Montevideo 2004.

- Rehabilitación: Bolonia 1973, Gijón 1985, Panamá 2001, Madrid 2004, A Coruña 2012, Antigua Guatemala 2012.

- Recuperación: Palermo 1993, Lima 2014.

- Preservación: Florencia 2016.

\section{Estrategias transformadoras}

- Reforma interior: La Coruña 2012.

- Renovación: Santiago de Chile 1990, Maracaibo 1999.

- Recualificación: Gijón 1985, Valladolid 1997, Roma 2003, Milán 2012.

\section{Estrategias integrales}

- Revitalización integral: Recife 1980, Gijón 1985, Málaga 1990, Salvador de Bahía 1991, La Habana 1994, Zaragoza 1997, San Salvador 1998, Ciudad de México 2000, Madrid 2004, Montevideo 2004 (ordenación, mejora), Comayagua 2005, Santo Domingo 2006, Santa Cruz de la Sierra 2008, Cartagena 2008, Nápoles 2011, Buenos Aires 2015, Asunción 2015, San José de Costa Rica 2015. 


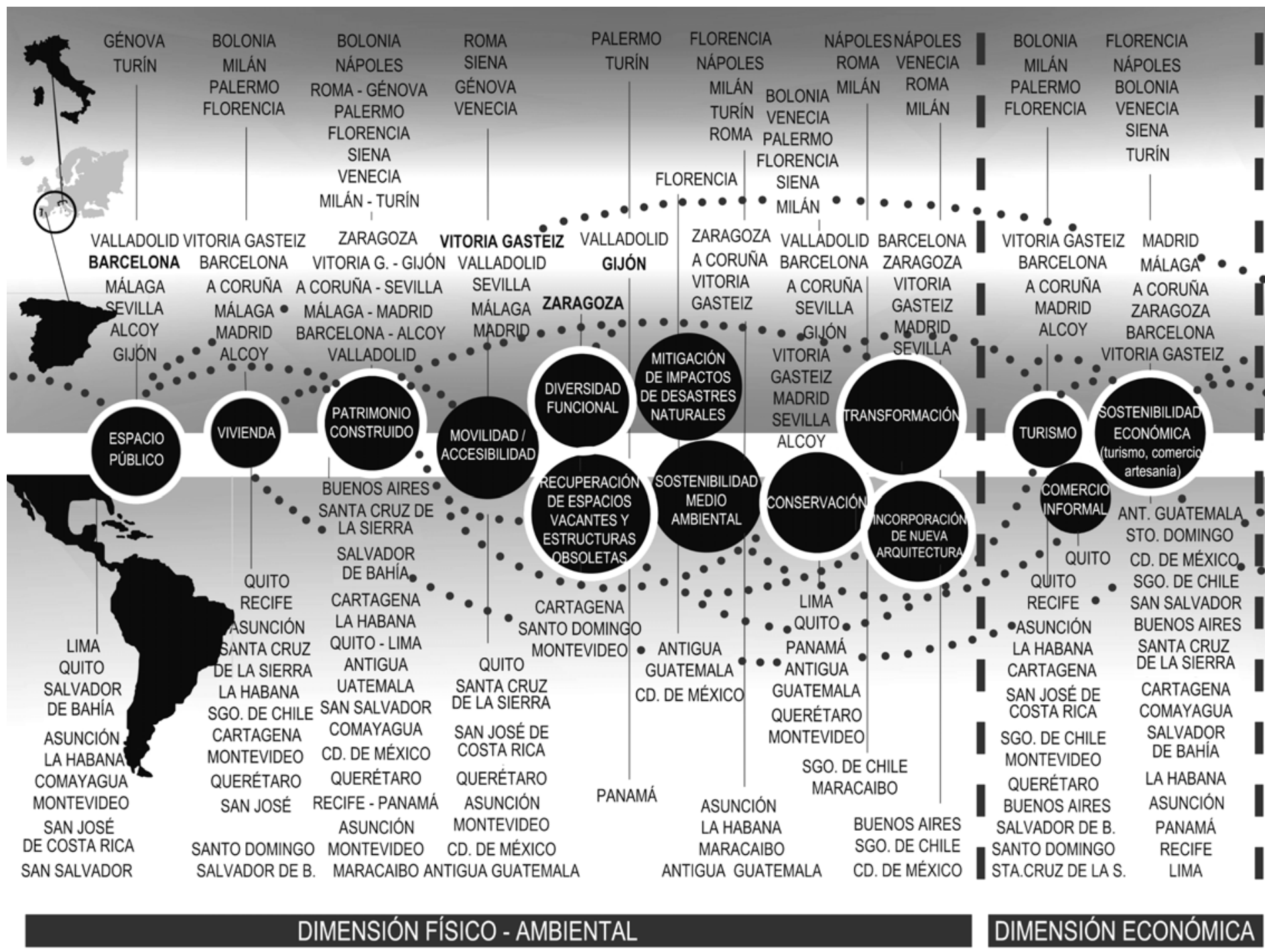

Figuras 3.a. y 3.b. Intervenciones en CH. Fuente: elaboración propia, 2017 


\section{Problemáticas y estrategias para la intervención y gestión en centros históricos de Italia, España y América Latina}

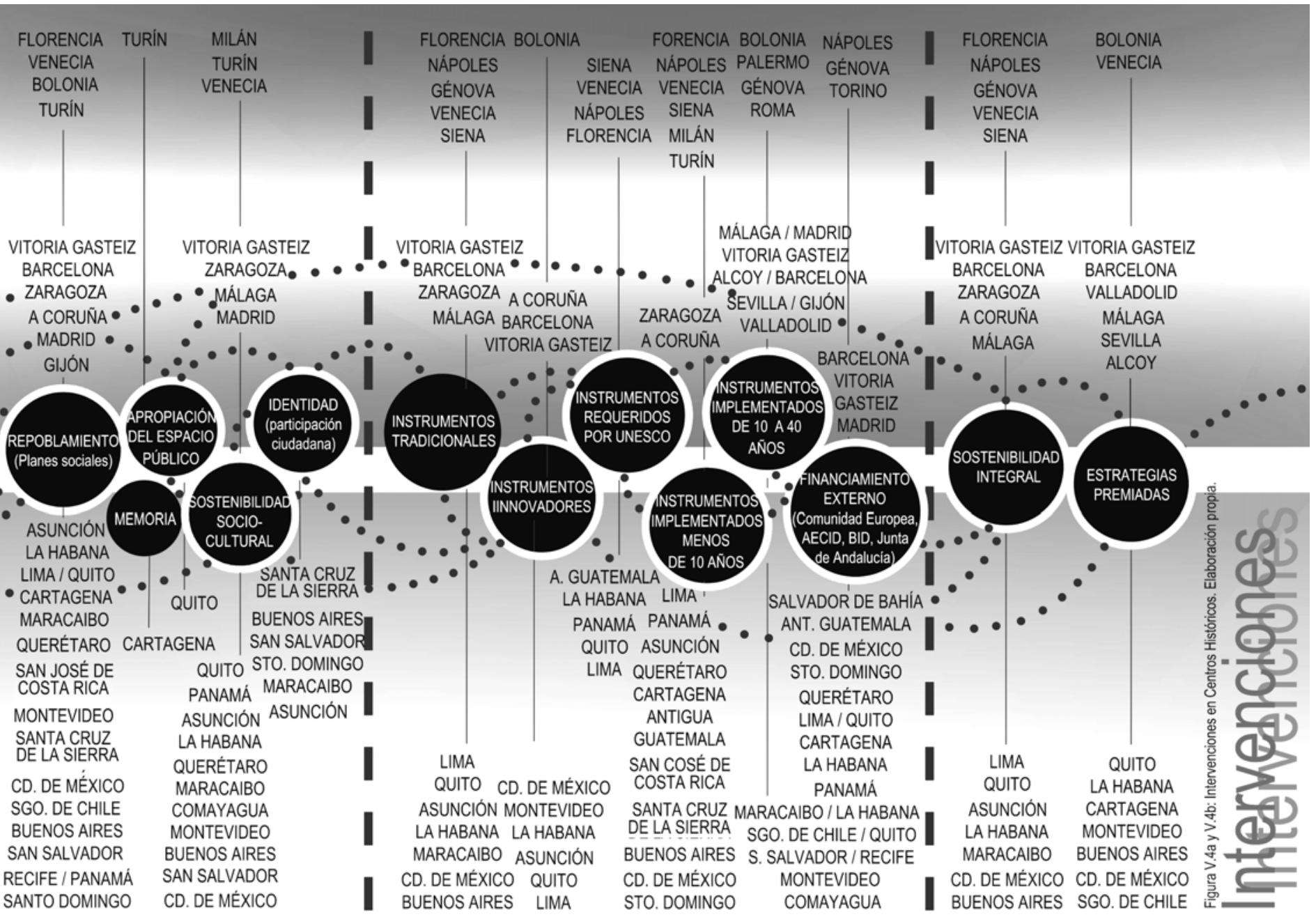


- Rehabilitación integral: Vitoria Gasteiz 1983, Barcelona 1987, Quito 1989, Málaga 1990, Alcoy 1991, Génova 2001, Lima 2014

- Regeneración: Gijón 1985, Valladolid 1997, Génova 2001, Turín 2011, Milán 2012, Venecia 2012.

Para la puesta en práctica de estas estrategias, se han identificado como aportes instrumentos operacionales, de planificación y los organismos de gestión e instituciones de financiación, que se desarrollan en el punto 3.2 .

Como síntesis del análisis, se identifica la implementación de estrategias más conservadoras y transformadoras en ciudades de Italia y España, y el predominio de estrategias más integrales, principalmente de revitalización, en los $\mathrm{CH}$ de ciudades de AL. Estas se enmarcan generalmente en planes de sector implementados en el ámbito de planes urbanos que definen instrumentos legales para su intervención. En gran parte de los casos se llevan adelante mediante organismos de gestión pública del $\mathrm{CH}$, y en algunos casos se desarrollaron organismos mixtos, en los que participan actores privados que facilitan la actuación. A su vez, existen instituciones financiadoras que contribuyen con los gobiernos municipales, como la Unión Europea en el caso de los CH de España e Italia, la Agencia Española de Cooperación Internacional (AECID) y la Junta de Andalucía, que intervienen tanto en España como en países de AL, entre otras fuentes que colaboran con instituciones internacionales de financiamiento, como el Programa de Naciones Unidas para el desarrollo (PNUD), y el Banco Interamericano de Desarrollo (BID).

\subsection{Nuevos enfoques}

A partir de la identificación de las experiencias innovadoras, su análisis posibilitó el reconocimiento de distintos aportes en las dimensiones en que se ha desagregado el paradigma del Urbanismo Sostenible.

Dentro de la dimensión físico-ambiental, se identificaron estrategias que, en pos de la recuperación del patrimonio material, han propuesto actuaciones relevantes, como la de Bolonia en Italia. Esta fue, como se expresó, una de las primeras experiencias iniciadas en la década del 70 llevadas a cabo desde la gestión estatal, que más influyó en sucesivas intervenciones en $\mathrm{CH}$ de ciudades italianas como Ferrara, Brescia, Como, Módena y Vicenza, pero también en ciudades fuera de Italia de variados países del mundo. Su aporte en la 


\section{Problemáticas y estrategias para la intervención y gestión en centros históricos de Italia, España y América Latina}

rigurosa metodología de análisis morfológico determinando tipos arquitectónicos (conjuntos monumentales, tipologías de edificios) y su exigente política de conservación (restauración, repristino y reconstrucción), sumados a la fuerte apuesta social del CH (dimensión socio-cultural) la constituyeron como un caso paradigmático, innovador para la época.

A su vez, se han reconocido destacadas operaciones en el espacio público, como el caso de Barcelona, donde desde la Oficina de Proyectos Urbanos se desarrollaron dos PERI a principios de los 80 para Ciutat Vella (barrios del Raval y Sector Oriental) y el Plan de Rehabilitación Integral de la Ciutat Vella de Barcelona, a finales de la misma década. Ambos PERI estuvieron orientados a la aplicación de intervenciones en el espacio público a escala de la denominada cirugía urbana en el tejido, a través de rehabilitación de espacios públicos, equipamientos, infraestructuras y viviendas. El Plan de Rehabilitación plantea una intervención integral, con actuaciones sobre el patrimonio edilicio y público, las infraestructuras, el paisaje urbano, la identidad cultural, con fortalecimiento de la cohesión social y de las funciones residenciales, culturales, económicas y de servicios, y hace hincapié en la accesibilidad y la movilidad.

Teniendo a Barcelona como guía, desde el Ayuntamiento de Alcoy se crea el Plan ARA. Se definen en el $\mathrm{CH}$ cinco áreas de intervención con el propósito de detener la degradación física-ambiental y socio-económica e iniciar un proceso de regeneración, rehabilitando y revitalizando el $\mathrm{CH}$ con actuaciones de calidad de mínimo costo de mantenimiento y de carácter pedagógico. Para ello, se convoca a arquitectos de renombre. Esta experiencia es otra de las consideradas paradigmáticas, y resultó valiosa y precursora para la época. Concentró recursos económicos de la Comunidad Autónoma Valenciana para el desarrollo de actuaciones de gran calidad urbana y arquitectónica, en una época en que todavía Valencia no había incursionado en intervenciones de esa índole.

En otra de las comunidades autónomas españolas, en el País Vasco, Vitoria Gasteiz se presenta como un caso de más de treinta años de intervención y gestión en el CH, mediante el Plan Especial de Rehabilitación Integral iniciado a comienzos de los 80 y el Plan de Reactivación Integral del $\mathrm{CH}$ en funcionamiento desde 2009. Entre sus ejes presenta la recuperación de espacio público de calidad para funciones de estancia, descanso, juego y relación, en corredores, sendas, ejes, plazas y plazoletas, priorizando la presencia del verde en el marco del Plan de Movilidad Sostenible y Espacio Público. Su apuesta a la intervención en el espacio público a partir de la conservación patrimonial ha situado a esta ciudad como otro de los casos referentes. 
En el contexto latinoamericano, la ciudad de La Habana, en el marco de su Plan Maestro de Revitalización Integral de 1994, desarrolló el PEDI (Plan Especial de Desarrollo integral del CH, 2001), que presenta una intervención prioritaria en el espacio público. Inició sus actuaciones rehabilitando plazas principales, a las que se incorporaron parques y paseos urbanos, ejes, corredores, que acarrearon intervenciones en las distintas dimensiones. Este junto a otros aspectos de su intervención lo posicionan como caso paradigmático en AL.

Por su parte, Quito en el año 1989 elabora el Plan Maestro de Rehabilitación Integral de las Áreas Históricas, que plantea concebir el CH como espacio urbano representativo e inductor de nuevas y calificadas funciones en otras áreas de la ciudad, y lograr habitabilidad, accesibilidad y reactivación económica del $\mathrm{CH}$ conciliando la conservación del patrimonio. Una de sus prioridades fue la recuperación del espacio público, como eje para la rehabilitación del $\mathrm{CH}$, fomentando el sentido de identidad y pertenencia de sus habitantes mediante la apropiación social asociada a símbolos arquitectónicos o de memoria. Estas acciones acarrearon una intervención previa asociada a la dimensión económica: la organización del comercio informal, que había proliferado durante décadas en las calles del CH convirtiéndose en un gran mercado popular al aire libre con todos los inconvenientes que ello conlleva. Para la compleja tarea de gestionar la relocalización del comercio informal, surge el proyecto "Modernización del Comercio Popular", que traslada a los comerciantes a grandes mercados cerrados denominados "Centros Comerciales del Ahorro".

En esta misma dimensión, pero más asociada con la actividad turística, una de las primeras experiencias más comentadas en AL fue la intervención del CH de Salvador de Bahía. El reconocimiento de la UNESCO en el año 1985 del denominado "Pelourinho" volcó las miradas hacia el CH. De este modo, se inicia en el año 1991 el "Programa de Recuperación del Centro Histórico de Salvador", con el objetivo de revitalizar y reestructurar el CH creando un centro de atracción turística y de actividades recreativas de placer y diversión, con obras de restauración y rehabilitación de edificios históricos, para modificar dinámicas existentes. Se plantearon la introducción de nuevos usos asociados a la actividad turística y proponer estrategias de intervención enfocadas en la recuperación. Estas iniciativas originaron nuevas dinámicas en el $\mathrm{CH}$, que transformaron el sector en un enclave principalmente turístico con funciones asociadas a tal fin y con nueva población (gentrificación). 


\section{Problemáticas y estrategias para la intervención y gestión en centros históricos de Italia, España y América Latina}

Como se expresó, el incremento del turismo y la dependencia de una actividad económica son una amenaza también en la generación de áreas que funcionen como museos a cielo abierto, lo que se denomina "museificación" de los $\mathrm{CH}$, y que es un riesgo para las áreas históricas de ciudades donde el turismo es una de las actividades que cobra gran relevancia, como en Salvador de Bahía, Cartagena, Venecia, Florencia, Siena, Sevilla o Barcelona. El caso del Pelourinho se ha configurado como un interesante ejemplo de análisis para las administraciones, con el fin de evitar ciertos impactos negativos en las intervenciones de los $\mathrm{CH}$ de AL (ver figura 4.a).

Estos complejos procesos de intervención requirieron en la dimensión institucional la creación de instrumentos integrales de gestión. Vitoria Gasteiz, para la aplicación de sus planes, entendió como clave la creación a finales de la década del 80 de un organismo municipal con un modelo de gestión integral como la Agencia de Revitalización Integral de la Ciudad Histórica SA, que posee un funcionamiento similar al de una empresa privada.

En el contexto latinoamericano, muy tempranamente, en el año 1938, la ciudad de La Habana, con una fuerte apuesta al modelo de gestión estatal, sienta sus bases en la constitución de la Oficina del Historiador, organismo municipal autónomo, que desde el año 1981 posee presupuesto para rehabilitación y actúa como entidad líder en la toma de decisiones y financiamiento. Se desempeña bajo un marco legal especial, y funciona con un sistema empresarial, con la compañía hotelera Habaguanex SA para la explotación turística, la agencia de viajes San Cristóbal y la Inmobiliaria Fénix SA. Otro de los ejemplos en gestión pública en AL es Lima, que creó el "Programa Municipal para la Recuperación del CH PROLIMA" como institución líder en la gestión, recuperación, reactivación y promoción del Desarrollo Sostenible del $\mathrm{CH}$. Más recientemente, la Ciudad de México creó el "Fideicomiso $\mathrm{CH}$ de la Ciudad de México", que desde el año 2002 funciona como fideicomiso público dependiente del Gobierno de la ciudad. En su creación, en el año 1990, fue de carácter privado.

Con respecto a los instrumentos de gestión mixta en el contexto europeo, Barcelona desarrolló un instrumento novedoso para la época: la empresa mixta municipal Promocio Ciutat Vella PROCIVESA (luego denominada Foment de Ciutat Vella), que ha servido de inspiración para otras administraciones. En AL, el antecedente previo a este caso es la creación de CORDESAN, Corporación para el Desarrollo de Santiago, institución privada sin fines de lucro que fomenta la colaboración entre el Municipio, el sector privado y la comunidad. Una función 


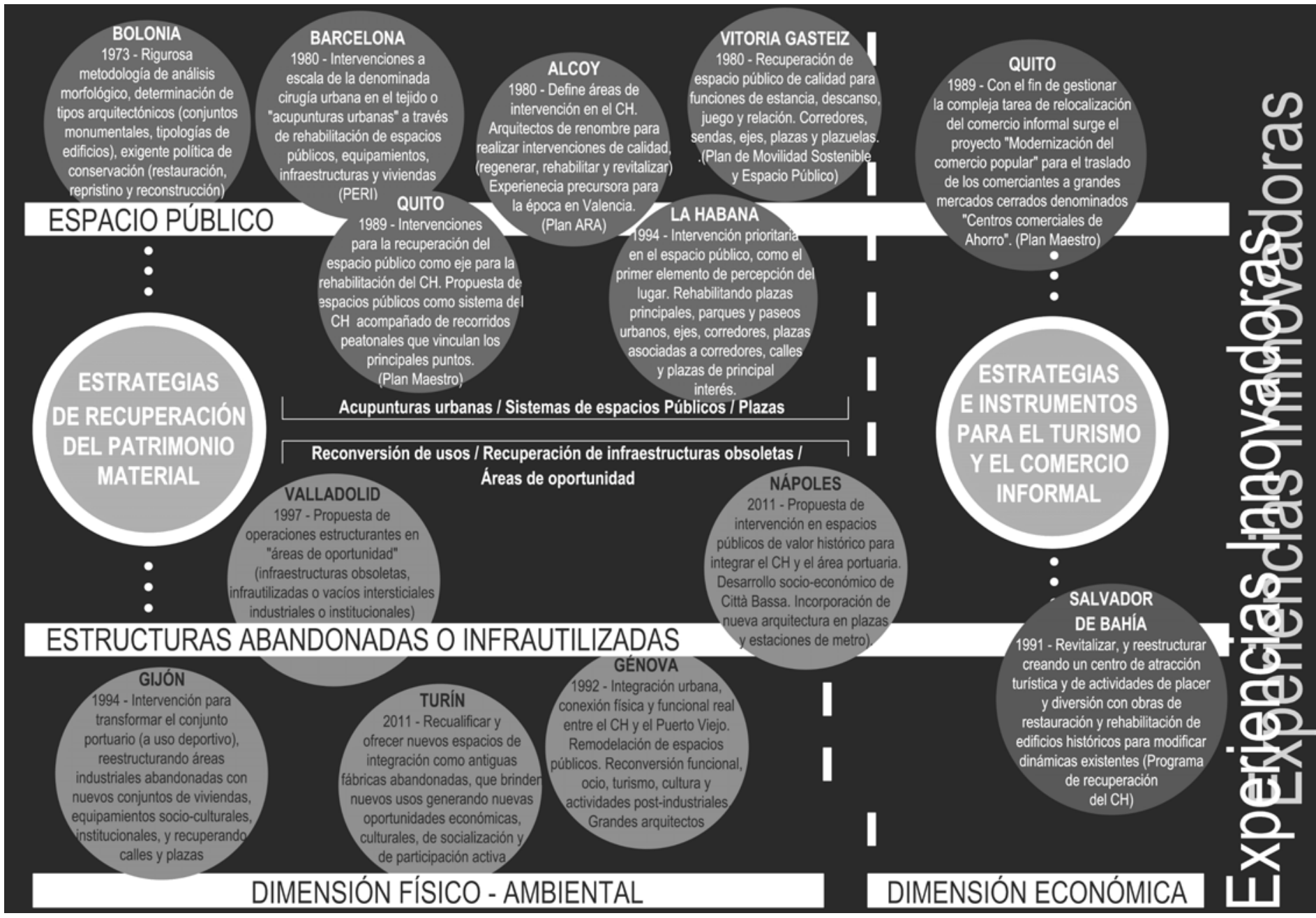

Figura 4.a. Experiencias innovadoras, dimensión físico-ambiental / dimensión económica. Fuente: elaboración propia, 2017 
similar desempeña la "Fundación del CH de la Ciudad de México (FCHCDM)" o "Fundación Carlos Slim”, asociación civil sin fines de lucro, constituida con el apoyo económico de empresas privadas para colaborar con los gobiernos en la revitalización y restauración del CH.

Sin embargo, el primer caso latinoamericano de gestión mixta y funcionamiento semejante al instrumento catalán es el "Patronato Panamá Viejo", ente administrativo mixto creado en 1995, sin fines de lucro, independiente y con autonomía para la toma de decisiones y manejo de fondos para la gestión. Al año siguiente, con el objetivo de la rehabilitación integral del CH se crea en Quito la "Empresa del CH (ECH)", pionera en AL en este tipo de gestión fomentada desde el Municipio, que recibe sus aportes financieros y del BID. Más recientemente, en el año 2016, se crea en Asunción el "Laboratorio Abierto de Desarrollo Urbano (ASULAB)", que funciona como una "oficina del cambio", interfaz entre la gestión institucional y el impulso ciudadano, punto de conexión con agentes privados financiadores de proyectos en el $\mathrm{CH}$. (ver figura 4.a)

El desarrollo de estos instrumentos permitió la creación en la dimensión socio-cultural de políticas de vivienda enfocadas en el repoblamiento de los $\mathrm{CH}$. Resulta interesante destacar en Europa la citada experiencia de Bolonia, que ha promovido políticas de vivienda social con alto porcentaje de viviendas de promoción pública con el fin de mantener en el $\mathrm{CH}$ a las clases sociales más desfavorecidas y crear casas para obreros para frenar el despoblamiento. En este ámbito, Barcelona desarrolló intervenciones denominadas "acupunturas urbanas con esencia en la vivienda”, que produjeron la recuperación de equipamientos y la renovación de infraestructuras para el sector. También en España, en el mismo período, Vitoria Gasteiz fomentó la aplicación de intervenciones para fijar a la población residente, mantener y regenerar el tejido social, y se encuentra pensando estrategias para incentivar el alquiler de jóvenes en el $\mathrm{CH}$.

Por su parte, en AL las experiencias implementadas en Santiago de Chile, Montevideo, Recife y San José de Costa Rica merecen particular atención. Una de las primeras iniciativas para recuperar y fomentar la residencialidad en el CH fue la de Santiago de Chile, que creó el Plan de Repoblamiento de Santiago (1990). Con el objetivo de densificar sectores urbanos y consolidar áreas centrales con pérdida de población, se propuso recuperar y fortalecer el rol residencial para generar beneficios sociales, económicos y ambientales, y beneficiar a personas sin vivienda con interés de vivir en el centro. 


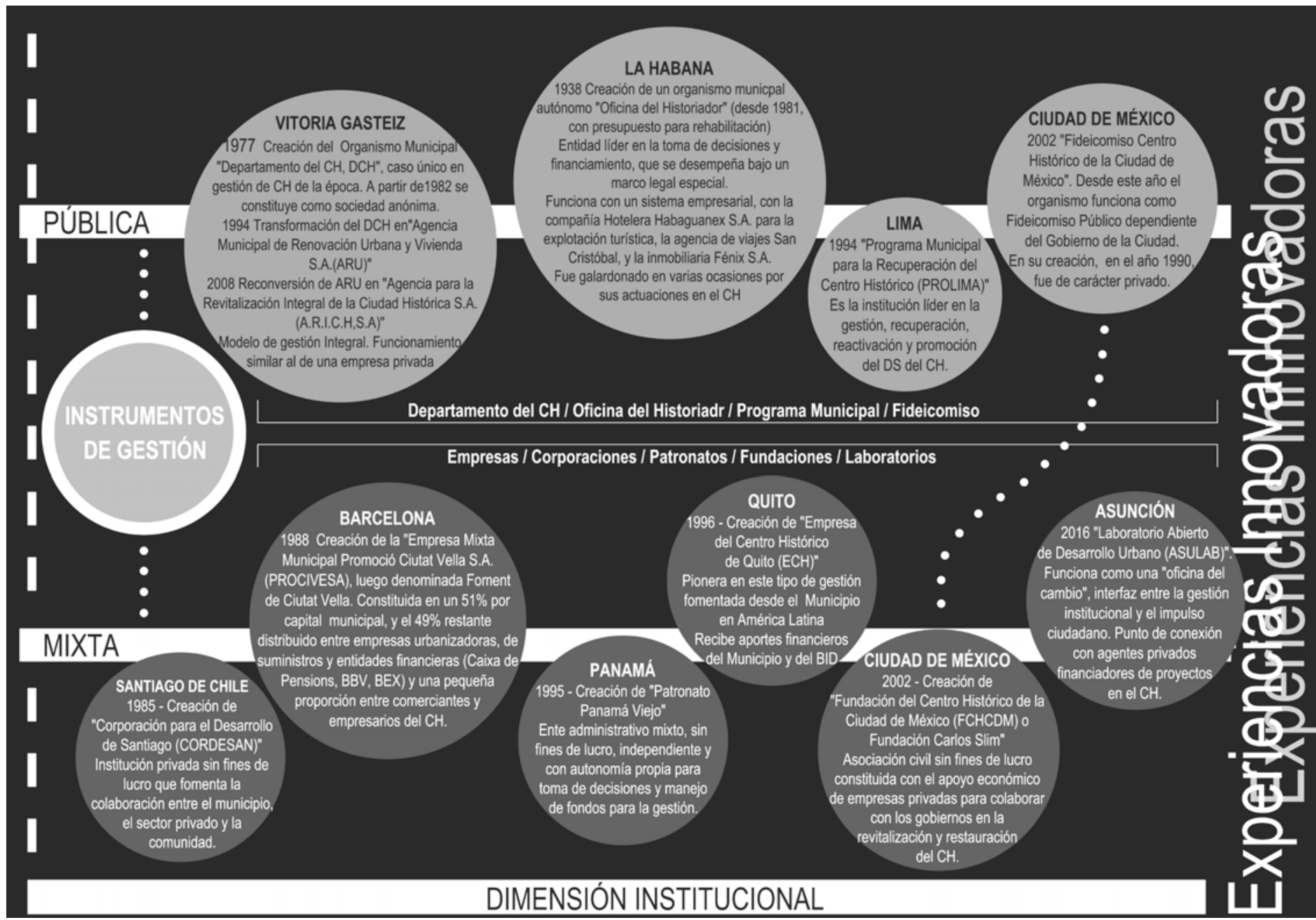

Figura 4.b. Experiencias innovadoras, dimensión institucional. Fuente: elaboración propia, 2017 
Para esa fecha, en Montevideo, con el fin de fomentar el repoblamiento defendiendo un hábitat policlasista e integrado, se desarrolla un sistema de cooperativas de viviendas para la recuperación de edificios históricos de la Ciudad Vieja o la construcción de obra nueva, y el incremento de la población residente. La intendencia de Montevideo facilita el acceso a la tierra a través de licitaciones para la adquisición de terrenos. Las cooperativas permiten que un mismo inmueble genere varias unidades habitacionales, exoneradas de contribución inmobiliaria. Las tierras son vendidas a las cooperativas con subsidios altos y largos plazos, sin intereses, para facilitar el acceso.

Otra de las propuestas singulares ha sido el Programa "Morar no centro" en Recife (20022005). Propuso incentivos para la vivienda y adecuación de edificios con fuentes oficiales de financiación, destinados al Programa de Arrendamiento Residencial (PAR). Dicho programa interviene los edificios para la puesta en valor de unidades habitacionales y su posterior alquiler con posibilidad de compra al finalizar el período de arrendamiento.

Finalmente, el gran despoblamiento y pérdida de vitalidad que paulatinamente está sufriendo el CH de San José de Costa Rica incentivó medidas como la rehabilitación de edificios abandonados que solo ocupan con usos la planta baja. Se promueven viviendas para funcionarios públicos que trabajan en el centro y que viajan diariamente desde barrios periféricos, junto al desarrollo de otras actividades complementarias permanentes que aseguren un uso constante del espacio público.

Por otra parte, para fomentar la inserción socio-laboral, se instituyeron principalmente en España y AL Escuelas Taller de los CH. En España, en 1985 se crea el "Programa de Escuelas Taller y Casas de Oficios”, que fue trasladado a AL a través de AECID por medio del Programa "Aprender Haciendo" (1991-2014), que ha alcanzado a numerosos CH latinoamericanos. En 2013 se crea la "Red de Escuelas Taller de AL".

\section{Consideraciones finales}

\subsection{Sobre las problemáticas e intervenciones}

Considerando la relación entre las problemáticas e intervenciones implementadas, que han derivado en el desarrollo de diversas estrategias en el marco de planes, y haciendo foco en los vínculos, similitudes y diferencias entre los diversos casos, se podría concluir que en AL 
la dimensión físico-ambiental presenta el mayor porcentaje de problemáticas, seguida por la socio-cultural, la económica y la institucional. En este contexto, es evidente el mayor deterioro físico-ambiental que presentan los $\mathrm{CH}$ de $\mathrm{AL}$, asociado a problemas institucionales superiores que junto con las problemáticas económicas terminan impactando también la dimensión socio-cultural. Mientras que en el contexto europeo, la dimensión socio-cultural cobra más relevancia, vinculada principalmente con la disminución y el envejecimiento de la población residente y con la gentrificación.

Del análisis también se pueden deducir las tipologías de problemas que dentro de cada dimensión afectan en mayor o menor medida a los $\mathrm{CH}$. Con respecto a la dimensión físico-ambiental, el deterioro físico general, la pérdida de centralidad funcional y el desequilibrio funcional, junto con la pérdida de centralidad urbana, la disminución de la función residencial y la alta exposición a desastres naturales son los conflictos más frecuentes. En la dimensión socio-cultural, la disminución de la población residente lidera la lista de problemáticas, seguida por la gentrificación, la marginalidad, violencia, drogadicción y delincuencia, y la invasión y ocupación del espacio público, ligados a la escasa valoración de este. Con respecto a la dimensión económica, la especulación inmobiliaria y los impactos negativos del turismo se presentan como prioritarios, y en cuanto a la dimensión institucional, las tres problemáticas que prevalecen en igualdad de jerarquía son la deficiencia institucional con la falta de instrumentos, la escasez de recursos y la deficiencia en los procesos de seguimiento y control.

Con respecto a las dimensiones que más intervenciones tuvieron, el mayor porcentaje se sitúa en la dimensión físico-ambiental, seguida por la institucional, la económica y la socio-cultural. También pueden reconocerse las tipologías de intervenciones más usuales en el interior de cada dimensión:

- en la dimensión físico-ambiental, las intervenciones se focalizan principalmente en la recuperación del patrimonio construido, con actuaciones en la vivienda, el espacio público y la movilidad y accesibilidad;

- en la dimensión socio-cultural, la mitad de las intervenciones se centran en el repoblamiento de los $\mathrm{CH}$, con un notable interés en la sostenibilidad socio-cultural;

- la dimensión económica presenta un claro interés en las intervenciones orientadas a la sostenibilidad en este aspecto, con una fuerte apuesta al turismo y

- en la dimensión institucional, se demuestra que aproximadamente la mitad de los casos 
poseen instrumentos implementados de diez a cuarenta años atrás, y la otra mitad con instrumentos de menos de diez años de aplicación. Mayoritariamente, se desarrollan instrumentos tradicionales con financiamientos externos.

\subsection{Sobre las experiencias integrales}

Bolonia, a pesar de adolecer para la mirada actual del abordaje de varios aspectos, para la época en que fue implementada resultó una propuesta mucho más integral e innovadora en relación con intervenciones coetáneas. Propuso una conservación integral o estructural, mantener a las clases sociales más débiles, frenar el despoblamiento, conservar la artesanía y los comercios típicos, incorporar equipamientos barriales y promover el turismo. En España, Vitoria Gasteiz destaca por la intención integral de intervenir su patrimonio construido (espacio público, viviendas, equipamientos, infraestructuras y accesibilidad), conservar y revalorizar el patrimonio histórico artístico, fijar a la población residente y mantener y regenerar la composición del tejido social. Barcelona, por su parte, se constituye como otro de los casos integrales, con intervenciones sobre el espacio público y privado, las infraestructuras, el paisaje urbano y la identidad cultural, que fortalecen la cohesión social y las funciones residenciales, económicas, de servicios, accesibilidad y movilidad. Las tres propuestas se cimentan sobre una sólida base institucional de gestión pública y mixta.

En AL, las actuaciones en Quito y La Habana se presentan como casos significativos tanto desde su intervención como desde el desarrollo de instrumentos de gestión. Quito ha desarrollado intervenciones con el obetivo de concebir al $\mathrm{CH}$ como espacio urbano representativo e inductor de nuevas y calificadas funciones en otras áreas de la ciudad, y lograr la habitabilidad, accesibilidad y reactivación económica del CH. En el caso de La Habana, se han propuesto como objetivos renovar y revitalizar el $\mathrm{CH}$, y lograr la sostenibilidad cultural, medioambiental, social y económica. Para ello plantean mejorar las condiciones de vida de los más necesitados a través de programas de revitalización social y la restauración de edificios, desarrollar programas sociales y patrimoniales, favorecer la apertura económica y el desarrollo turístico, con ejes en el suelo urbano y la economía local, la vivienda (edificios con altos niveles de hacinamiento y degradación), el equipamiento comunitario, el espacio público y las redes de infraestructura y medioambiente, pero principalmente en la cultura, la identidad y la justicia social. (ver figura 4.c.) 


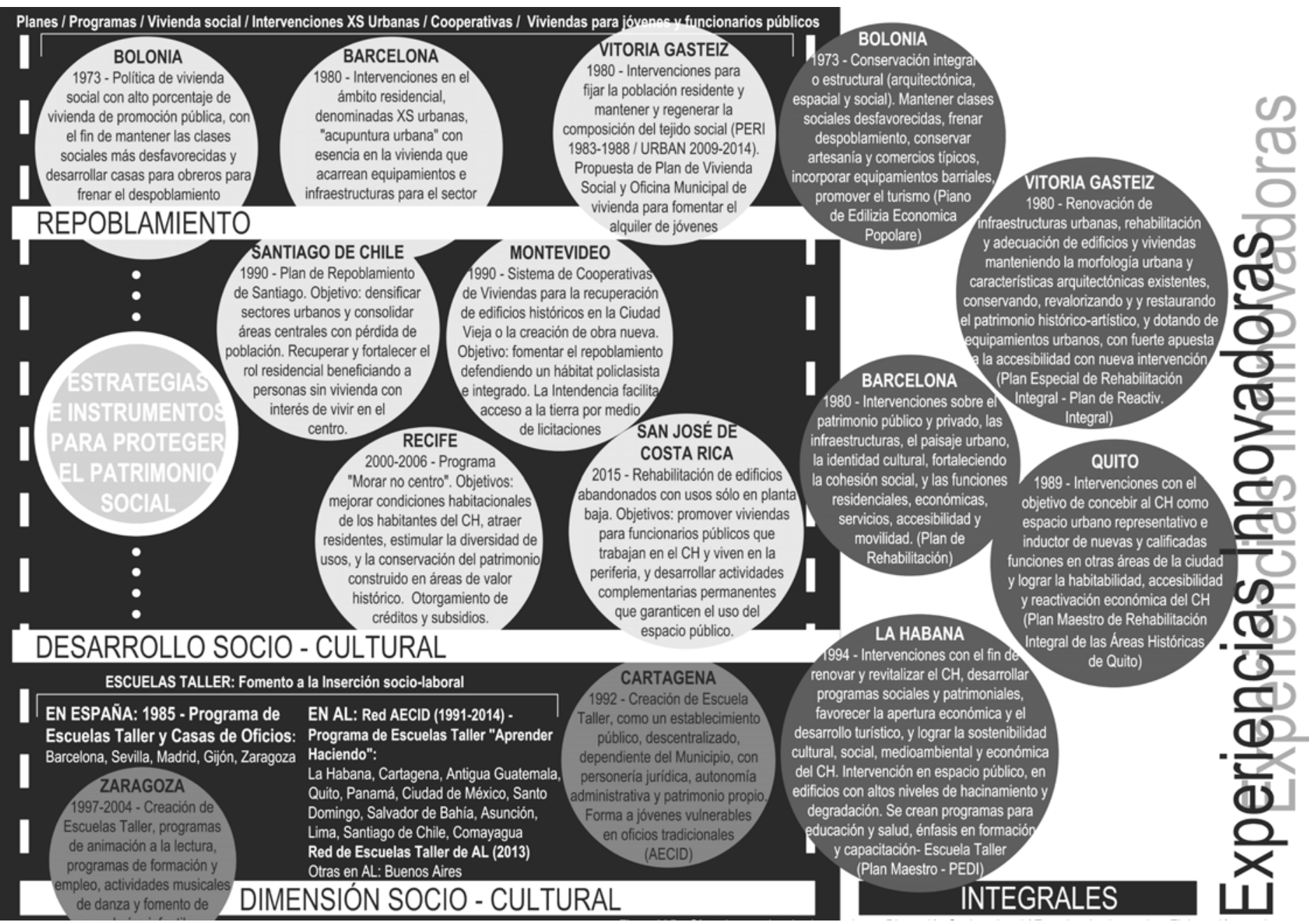

Figura 4.c. Experiencias innovadoras, dimensión socio-cultural/ experiencias integrales. Fuente: elaboración propia, 2017 
Sin embargo, a excepción de algunos casos, la sostenibilidad integral continúa siendo un desafío, dado que algunas problemáticas o fenómenos permanecen como retos por abordar o evitar, como la conservación de la población residente y las actividades económicas tradicionales, el repoblamiento, la gentrificación, la museificación derivada del turismo, el comercio informal, el deterioro del patrimonio construido con la siguiente ocupación de grupos sociales desfavorecidos y la proliferación de la drogadicción, la inseguridad y la violencia.

Por último, algunas estrategias siguen siendo eje de debates, como el diálogo entre la nueva arquitectura y el patrimonio histórico construido de los CH. En el ámbito institucional, la gestión integral sigue requiriendo en muchos casos la creación de instrumentos competentes y de convicción y continuidad política para alcanzar los objetivos propuestos en los proyectos urbanos. A su vez, las metas perseguidas en los planes generalmente se enfrentan durante el proceso de implementación a situaciones o impactos no esperados, que modifican los resultados deseados.

\section{Bibliografía}

CESARI, Carlo (1993). "El proceso de conservación y rehabilitación en Italia”. Revista Científica de ICOMOS, Núm. 2, Galicia, España.

ETULAIN, Juan Carlos, GONZÁLEZ BIFFIS, Alejandra (2014). "La evolución del proyecto urbano. Intervenciones urbanas y cambios de paradigmas". En Revista Cuaderno Urbano, Espacio, cultura y sociedad. Vol. 17. Núm. 17. Nobuko Eudene, Editorial de la Universidad Nacional del Nordeste.

GAJA DÍAZ, Fernando (2001). "Intervenciones en centros históricos de la Comunidad Valenciana”, Consejo de Obras Públicas, Urbanismo y Transporte, Dirección General de Arquitectura y Vivienda, Universidad Politécnica de Valencia, Departamento de Urbanismo.

POL MÉNDEZ, Francisco (1993). “La recuperación de los centros históricos en España”. Jornadas de Estudio "Recuperación de centros históricos". España. Disponible en www.dialnet. unirioja.es.

RODRÍGUEZ ALOMÁ, Patricia (2008). "El centro histórico: del concepto a la acción integral”. En Revista Centro-h, núm. 1, OLACCHI, Quito.

RODRÍGUEZ ALOMÁ, Patricia (2013). "La gestión del desarrollo integral de los centros históricos en Latinoamérica”. En Carajillo de la ciudad, Revista digital del Programa en gestión de la ciudad. Café de las ciudades, núm. 16. 
SANTAMARÍA COMALLONGA, Joaquín (2013). "Centros históricos: análisis y perspectivas desde la geografía”. En GeoGraphos, Revista Digital para estudiantes de Geografía y Ciencias Sociales, Vol. 4, Alicante.

TROITIÑO VINUESA, Miguel Ángel (2003). "La protección, recuperación y revitalización funcional de los centros históricos". En Colección Mediterráneo Económico: "Ciudades, arquitectura y espacio urbano", núm. 3, Cajamar.

VALENZUELA RUBIO, Manuel (2000). "La regeneración de los cascos históricos en España. El programa URBAN, dinero comunitario para una estrategia global”. En III Jornadas de Geografía Urbana: Oportunidades de desarrollo urbano sostenible para los conjuntos urbanos históricos. Universidad de Burgos, España.

WANDEMBERG BOSCHETTI, Juan Carlos (2015). “Sostenible por diseño, Desarrollo económico, social y ambiental”. 